\title{
WHERE TO START AND HOW TO JUDGE? FIRST AND THIRD GRADERS' MEASUREMENT CONCEPTIONS
}

\author{
Ana-Maria Haiduc, PhD Graduate Student, Purdue University \\ Laura Bofferding, Associate Professor, Purdue University \\ Mahtob Aqazade, PhD Graduate Student, Purdue University \\ Lizhen Chen, PhD Graduate Student, Purdue University \\ Sezai Kocabas, PhD Graduate Student, Purdue University
}

\begin{abstract}
We analyzed students' responses to a series of broken ruler measurement tasks in the form of incorrect worked examples. The measurement tasks challenged students' initial conceptions of where the measurement starts and how to determine the overall length.

\section{Brief Report}

Typical difficulties with measuring include aligning the object with the ruler at one instead of at zero, aligning the object at the ruler's edge, or incorrectly identifying the number at the end point of the object as the length regardless of where the object's beginning point is aligned with the ruler (Clements, 1999; Drake, 2014; Lehrer et al., 1998). Broken ruler tasks are often used to highlight where students are on the measurement trajectory, but when presented as worked examples, can also help them confront their confusions. An orientation toward focusing on the trajectory of students' learning is prevalent in the learning through activity approach (Simon et al., 2010). Key to such approaches is a focus on choosing task sequences that could promote reflective abstraction (Simon et al., 2010; Piaget, 1960). The tasks are meant to expose students to potential inconsistencies in their thinking, help them make sense of them, and advance their thinking to resolve the inconsistencies (Kamii, 2006).

As part of a larger study, 32 first-graders and 37 third-graders responded to a series of measurement tasks in the form of incorrect worked examples. We chose measurement problems to challenge students' initial conceptions about where a measurement starts and how to determine the overall length. We provided students with a worked example of an incorrectly solved broken ruler task for the students to "debug." The task had only one erroneous component: the length measurement of the item. We created follow-up questions (which we presented during the post-test) showing a screwdriver placed on a ruler in different places, based on their responses to the initial task. To determine how their continuous measuring ideas related to their discrete measurement ideas, we included an example of a student measuring with blocks. The students associated the concept of the beginning point to start measuring with zero, one, and edge. This study tells what first and third graders know about measurements when working a sequence of measurement tasks on paper and it provides useful insight into their conceptions of measurements.
\end{abstract}

Acknowledgments. This research was supported by an NSF DRL ITEST Grant \#1759254.

\section{References}

Clements, D., \& Sarama, J. (2009). Learning and teaching early math the learning trajectories approach (Studies in mathematical thinking and learning). Routledge.

Drake, M. (2014). Learning to measure length: The problem with the school ruler. Australian Primary Mathematics Classroom, 19(3), 27-32

Kamii, C. (2006). Measurement of length: How can we teach it better? Teaching Children Mathematics, 13(3), 154158.

Lehrer, R., Jenkins, M., \& Osana, H. (1998). Longitudinal study of children's reasoning about space and geometry. Designing learning environments for developing understanding of geometry and space, 1, 137167.

Piaget, J. (1960). The child's conception of geometry. Basic Books.

Simon, M., Saldanha, L., McClintock, E., Akar, G. K., Watanabe, T., \& Zembat, I. O. (2010). A developing approach to studying students' learning through their mathematical activity. Cognition and Instruction, 28(1), 70-112. 